\title{
Apuntes
}

\section{Quince años de intervenciones en la Catedral Nueva de Cádiz}

Juan José Jiménez Mata

Arquitecto

Al hacerse cargo la Junta de Andalucía de las competencias patrimoniales, la Catedral Nueva de Cádiz era uno de los grandes edificios monumentales en mayor grado de abandono. A partir del año 1987 se ha actuado sobre el edificio sin grandes paréntesis.

\section{Trabajos previos:}

(1987) Se iniciaron los trabajos de levantamiento de planos con apoyo fotogramétrico, así como la redacción de un diagnóstico basado en la inspección del edificio, detección de patologias, selección e interpretación de la documentación existente, especialmente sobre los graves problemas de deterioro de la piedra.

Restauración de la cubierta de la sacristía, sala capitular y linterna: (1988) Las obras, por importe de 6.595 .939 ptas. a cargo de la Consejería de Cultura, atendieron problemas urgentes de filtraciones, permitiendo una primera aproximación a las características constructivas ocultas del edificio.

Colocación de redes en el interior del Templo:

(1989) Los graves peligros por la continua caída de lajas de piedra se eliminaron mediante la colocación de una red de fibra resistente al deterioro de la luz y otros agentes. A cargo de la Consejería, por importe de 9.042.488 ptas.

Restauración parcial exterior $1^{\text {a }}$ fase:

(1991-92) Estas obras tuvieron por objeto comenzar la necesaria protección del edificio frente a los agentes externos, especialmente las filtraciones de agua, vehículo del transporte de sales dañinas en el interior de las fábricas, bien por aportación desde el exterior (atmósferas salinas) o por disolución de sales ya depositadas en las fábricas, especialmente en las juntas de las mismas. Las obras se extendieron a las cubiertas (excepto cúpulas) y a las fachadas principal y de poniente. Su importe ascendió a 109.461.550 ptas., a cargo de la Sociedad V Centenario.

Restauración parcial exterior $2^{\text {a }}$ fase:

(1993-94) Continuación de la anterior en las fachadas este y sur, por importe total de 54.928.240 ptas, a cargo de la Consejería.

Restauración parcial exterior $3^{\text {a }}$ fase:

Esta tercera fase de obras exteriores, por un importe de 71.833 .013 ptas., abordó la finalización de las obras de protección del edificio frente a los agentes atmosféricos, especialmente para evitar la entrada de humedades por las cúpulas superiores y paramentos del cuerpo alto de la nave central y del crucero. Se sustituyó el azulejo amarillo que recubría la cúpula central del crucero, ya que el mismo se encontraba totalmente deteriorado, con el vidriado desaparecido o roto y el bizcocho disgregado. Se dispuso un nuevo revestido de azulejos, idénticos a los antiguos. La bóveda del presbiterio, cuya superficie exterior es de piedra caliza, se reparó mediante limpieza y rejuntado de las llagas con mortero de cal mejorado. Sobre las caras exteriores de las dovelas se aplicó un hidrofu- gante incoloro. El tambor de la cúpula del crucero, cuyo revestido de estuco color ocre se encontraba totalmente cuarteado y desprendido en muchos puntos, se sustituyó por nuevo estuco de cal mejorada, de color blanco marfil. Previamente se realizó la limpieza y neutralización de sales del soporte. Se realizó la reparación de elementos ornamentales en mal estado, como metopas, molduras, canes y cornisas del tambor, mediante la utilización de piezas de piedra caliza debidamente protegida, ancladas a la fábrica mediante pernos de acero inoxidable. Se protegieron las piezas que pudieron conservarse. Este proyecto contemplaba asimismo la apertura de la cúpula y colocación de una linterna, tal como habia previsto Juan Daura al cubrir el Templo, dejando un anillo de piedra en la cúpula de ladrillo por si ello se pudiese hacer en el futuro. Se realizó la apertura de luz, que hoy inunda el interior desde el cenit de la cúpula, pero no se pudo construir porque el Ayuntamiento de Cádiz denegó la licencia para la linterna.

Restauración parcial interior $1^{\text {a }}$ fase:

Se acometió por el Cabildo, con una subvención del Banco de Bilbao-Vizcaya, la reparación de los importantes daños causados por el incendio de agosto de 1992, que originó la destrucción de
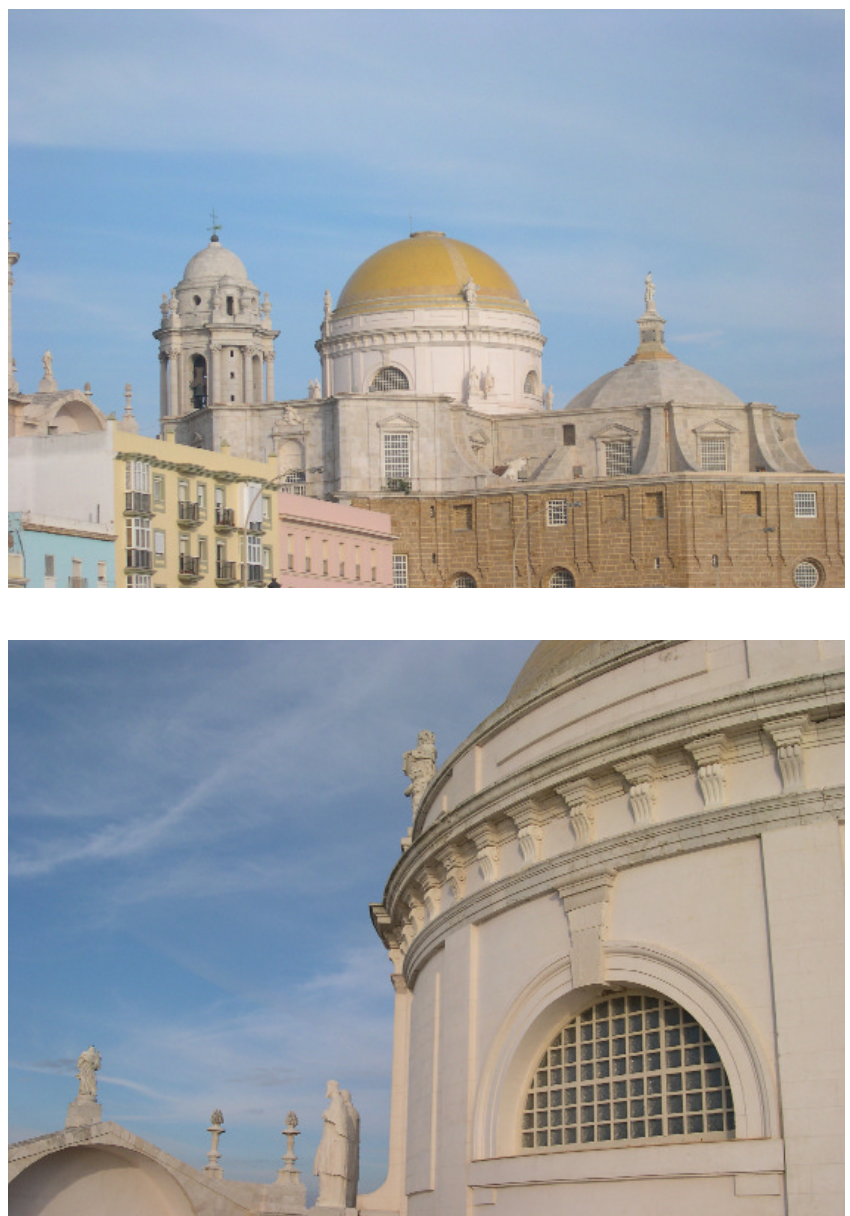


\section{$052-053$ \\ Información del PH}

Apuntes

\section{PH47 - Febrero 2004}

la puerta, del cancel del crucero en su extremo este y de gran parte de la embocadura, entablamento y cornisa superior, con ennegrecimiento de toda la fachada interior del crucero y bóvedas. Su importe fue de 26.628 .839 ptas. Consistió en limpieza de la piedra ennegrecida, aplicación de piezas de piedra de nueva labra en elementos destruidos, y reconstrucción del cancel de madera de cedro.

\section{Restauración parcial interior $2^{\text {a }}$ fase:}

Esta obra se incluyó en el Plan de Catedrales de la Administración Central, por un importe de 79.024.181 ptas. Tuvo por objeto mejorar las condiciones de las fábricas en el cuerpo alto del presbiterio y de los machones torales que lo enmarcan, donde existian diversos problemas: roturas mecánicas por concentración de tensiones en los ripios al estar los tendeles vacíos de mortero, por no haber fraguado los de cal primitivos, al estar ejecutados con aguas salobres, roturas en lajas por recristalización de sales, etc. Se procedió a la limpieza de llagas, inyección de morteros en tendeles, reposición de algunas piezas de piedra totalmente destruidas con objeto de recuperar las lineas fundamentales de arquitectura, desaparecidas, rellagueado de las fábricas, limpieza e hidrofugación de paramentos, etc.

Restauración parcial interior $3^{a}$ fase. Capilla de las Reliquias: Estas obras, por importe total de 394.170 euros, se encuentran actualmente en fase de terminación, siendo financiadas por el Plan de Catedrales de la Administración Central. Han tenido por objeto mejorar las pésimas condiciones del interior de la Capilla de las Reliquias. Se trata de la construcción de planta octogonal dispuesta en el centro de la girola, que surge ante la fachada trasera al mar. Fue el primer cuerpo que se elevó sobre los cimien- tos, por lo que es la zona más antigua del monumento, con una gran calidad en los labrados. La piedra caliza de la bóveda y cuerpos superiores presentaba abundantes roturas, así como coqueras y suciedad general en el resto. Se ha procedido al relabrado de las piezas indispensables para recuperar las líneas fundamentales perdidas de la arquitectura, así como a reponer con morteros de restitución los volúmenes fundamentales de la bóveda. Igualmente se ha procedido a la limpieza general y protección de piedras calizas y mármoles.

Restauración parcial interior $4^{\text {a }}$ fase:

Esta fase ha sido recientemente adjudicada por el Ministerio de Fomento, comenzando las obras el próximo día 2 de diciembre. Con un importe total de 1.094.681, este proyecto trata de la restauración de las yeserías del intradós de la cúpula del crucero y de los paramentos hacia el interior de la fachada principal, con los criterios ya expresados de proceder a la limpieza y protección de la piedra, rellagueados, colmatación de tendeles, así como a la restitución de los elementos fundamentales para la lectura correcta de las líneas arquitectónicas fundamentales en aquellos elementos fuertemente deteriorados.

Acondicionamiento de la tumba de Manuel de Falla:

Ha sido demolida la capilla construida en los años 50, que estaba dotada de un estilo inadecuado y se encontraba en un avanzado estado de deterioro. La intervención ha consistido en la puesta en valor de los paramentos de sillería de piedra ostionera y los caracteres espaciales de la cripta, antes ocultos. Su importe total, de 51.699 euros, ha sido aportado por la Consejería de Cultura y Diputación Provincial. Esta intervención se considera como una primera fase de lo que se entiende que podria ser la operación general de restauración de la cripta.

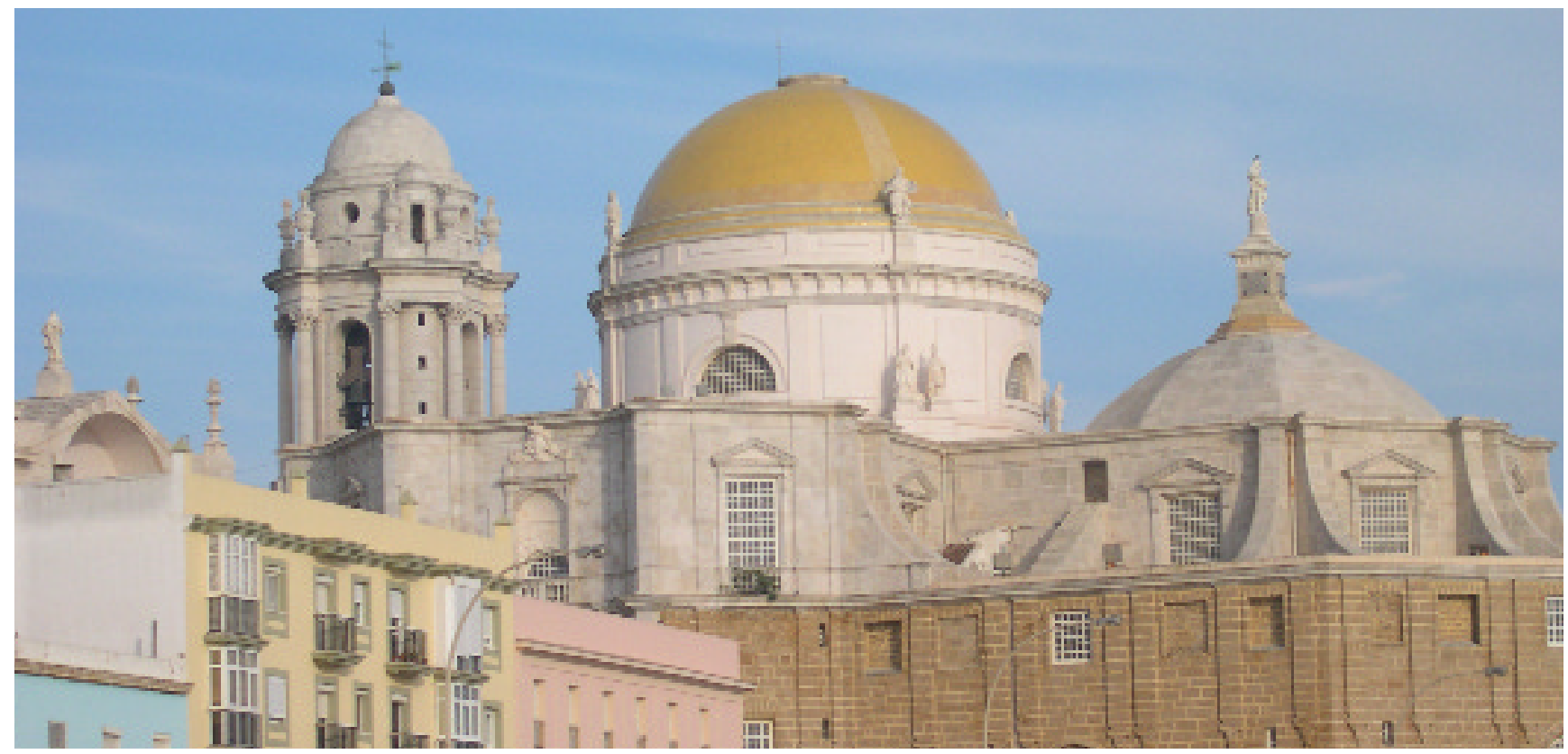

